\title{
Mathematics education in Turkey: at the crossroads of cultural, political and economic currents
}

\author{
Bharath Sriraman
}

Accepted: 23 May 2010/Published online: 6 June 2010

(C) FIZ Karlsruhe 2010

\begin{abstract}
In this opening introductory article to the issue of ZDM focused on mathematics education in Turkey, a short survey of the deep historical and cultural foundations of modern day Turkey is offered. This is followed by an outline of the development of researchers, as well as doctoral programs in mathematics education at universities in Turkey. The article also summarizes recently completed influential dissertations in Turkey and explains the aims and scope of this particular issue in relation to its conception and development.
\end{abstract}

Keywords Curriculum development · Doctoral programs in Turkey $\cdot$ History of Turkey $\cdot$ Mathematics education research in Turkey

\section{Opening remarks}

I am pleased and honored to write this extended introduction to this special issue of ZDM focused on mathematics education in Turkey. This issue came about due to the convergence of a number of forces, namely three consecutive summer visiting professorships at Gazi University in Ankara, Turkey from 2007 to 2009, which led to exposure to the work of researchers, and the task of mentoring of doctoral students in mathematics education in Turkey. In the fall of 2007 at Oberwolfach, I proposed the

B. Sriraman $(\bowtie)$

Department of Mathematical Sciences,

The University of Montana, Missoula, MT 59812, USA

e-mail: sriramanb@mso.umt.edu

\section{B. Sriraman}

Department of Central/SW Asian Studies,

The University of Montana, Missoula, MT 59812, USA idea of doing a special issue of ZDM focused on Turkey, which was supported by both Gabriele Kaiser and Kristina Reiss, with the suggestion of using as much time as needed to produce a high quality issue. Three years later, it has materialized. We, at ZDM, are proud to claim that this is the very first issue of its kind in a mathematics education research journal that focuses on Turkey, continuing in the vein of the Brazilian issue. In this introductory article, my intention is to introduce to the unfamiliar reader the complex position that Turkey holds in the world due to its location and a précis of its unique historical and cultural development; familiarize the reader with the conceptualization, progress and compilation of the issue; convey the present state of the art of mathematics education in this unique country. Several myths abound in the West about Turkey, its culture and people due to Orientalism. Edward Said (1935-2003), the Palestinian American literary/critical theorist used this term to describe a tradition, both academic and artistic, of hostile and deprecatory views of the East by the West, shaped by the attitudes of the era of European imperialism in the eighteenth and nineteenth centuries (Said, 1979). When used in this sense, it often implies an essentialized and prejudiced outsider interpretation of Eastern cultures and peoples.

\section{A brief history of Turkey (introducing ancient Turkey to dummies ${ }^{1}$ )}

The reader might be interested to learn that Turkish language and culture considerably influenced the languages and religions of southern and central Asia during the growth of the

\footnotetext{
${ }^{1}$ A serious introduction in the vein of the best-selling Dummies series in academia and otherwise in the USA.
} 


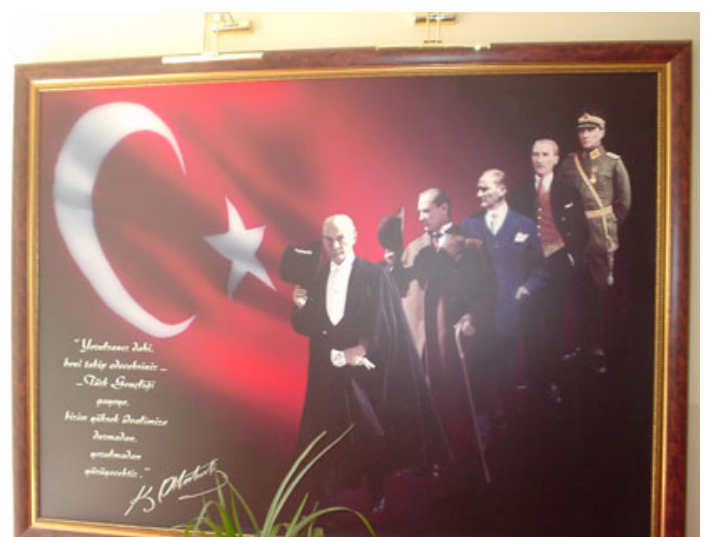

Fig. 1 Painting of Atatürk's transformation from soldier to statesman and to founder of modern Turkey

Moghul empire (Moghul is the Persian equivalent for Mongol). The Moghuls from the time of Tuglugh Timur (fourteenth century), who had embraced Islam when the Mongol empire was splintering, were Turkic in origin and Persian in culture. Descendants of the Moghuls in the Indian sub-continent, such as Akbar the Great and Shahjahan (the emperor who sanctioned the Taj Mahal) fused elements of Islam (particularly Sufism) with Hinduism. Although Turkish belongs to the Western sub-group of the Oghuz language group, the language contains the strong influence of Farsi (Persian) and Arabic, and these languages in turn contribute to nearly $40 \%$ of the vocabulary of Hindi and Urdu. The uniqueness of Turkish culture is its historical relationship to the Greco-Roman and Byzantine worlds, the Caliphate and the Caucuses, making the land a true crossroads of civilizations (Sriraman, 2007, 2008).

Modern day Turkey established in 1923 following the fall of the Ottoman empire in World War I is a secular democracy, Western in its political and economic orientation as a result of the reforms initiated by Mustafa Kemal Pasha (1881-1938), also known as Atatürk ${ }^{2}$ (the father of modern Turkey). In modern Turkish, the Arabic alphabet is eliminated and instead the Latin alphabet is used with linguistic symbols derived from French and German. I often posed the question: What does it mean to be Turkish? Interesting variations in responses arose. Many university intellectuals spoke of the various migrations, conquests and transmigrations of Turkic tribes within Asia and to an extent in Europe, the battles for supremacy on the Anatolian lands in postGenghis Khanates and agreed that the Osmanli (Ottoman) empire embraced, synthesized and nurtured numerous distinct cultures within its boundaries with an emphasis on fairness, respect and equality. In doing so, the Turkish language evolved from its Oghuz-Uighur roots into one that bore a strong influence of Farsi (Persian), Hindustani and

\footnotetext{
${ }^{2}$ See Fig. 1 for Atatürk's transformation from soldier to statesman, diplomat and leader.
}

Arabic. On the other hand, some intellectuals and people who tended toward modern Turkish nationalism emphasized more strongly the role and influence of the Selguk (سلجوقيانSaluqiyan in Farsi and Hindustani), in modern Turkish identity. For the uninitiated, the Selguks' origins lie in the Oghuz Turkic tribes (in today's geography, this is the region of Turkmenistan, Kazakhstan) that crossed the Volga and settled into the Black Sea steppes and Khorasan around the tenth century. Selguks became Persian in culture and language over time and then went onto capture Turkey, and in a sense created a beautiful synthesis of Turkish and Persian cultures. Another offshoot of this synthesis is found in India and Pakistan in what is now known as the Moghul culture, a synthesis of Mongol-Turkic-Persian cultures, one of the better consequences of the (infamous) Mongol invasions starting with Genghis Khan. In a nutshell, a documented history of various Turkic nations stretches for 1,500 years (!), from the sixth century onto 1921 (from small conglomerations of the Huns until the end of the Osmanli empire). In fact, history textbooks in Turkey contain detailed maps of the migrations, settlements and formation of Turkic nations over these 1,500 years, and modern day Turkey is the 16th nation!! When I queried about the reasons for frequent invasions and battles for Anatolia, the answer was simple: the various kingdoms lived in peace until some proclaimed themselves as the "big boss". Such a proclamation provoked neighboring Turkic kingdoms to attack. One should note that the Selguks were a highly Persianized culture and originally not Islamic to begin with. The Osmanli empire at its peak spanned three continents (North Africa, Eastern Europe and Asia) and epitomized both modern day ideals of justice, scientific research, tolerance, culture, equality as well as decadence. The Osmanli alliance with the Germans in World War I contributed to their demise, and the formation of independent modern day Turkey was through bloody battles fought on nearly all fronts of Turkey against the British, French and their allies. The colors of the Turkish flag (blood red with a white sliver moon and star) symbolize the reflection of the moon and star on the bloodied soil (Sriraman, 2008).

Leaving these pleasantries aside, I will next introduce the two co-editors from Turkey who were invited to participate in compiling and putting together this issue.

\section{Background and research of the co-editors}

Ziya Argün has studied in two main research areas. His first main area of research is in pure mathematics and his secondary area is mathematics education. In mathematics, his research areas are topics in functional analysis and operator theories. His doctoral dissertation completed at the University College of Wales in Aberystwyth was related to 
topics, which are fundamental subjects in functional analysis and operator theories such as Banach algebras, Arens semi-regularity of Banach algebras, multipliers and quasimultipliers on Banach algebras, and finite rank, approximations, compact, nuclear and integral operators on Banach spaces. He has successfully published some papers in these topics such as:

(a) On Quasi-Multipliers. Studia Mathematica, 108(3): 218-245 (1994).

(b) On the Arens semi-regularity of weighted group algebras. Glasgow Math J 36:269-271 (1994).

(c) Multipliers and Non-Associative $\mathrm{H}^{*}$.Algebras. Math Japonica 39(2) (1994).

After his dissertation, he supervised two doctoral theses in functional analysis. In these theses, his doctoral students researched topics such as vector valued functions, vector measures, the Phillips property, the weak Phillips property, the Schur property and Grothendieck property, which are part of geometric properties of Banach spaces, and as a result published some papers in these topics such as:

1. On the relationship between the weak Property and Arens regularity. Indian Journal of Mathematics 48(2):139-152 (2006)

2. Geometric properties of Banach spaces, Communications, Ankara University, Faculty of Sciences (2005).

3. Arens semi-regularity of co-sum of the Banach algebras. Journal of the Institute of Science and Tech. of Gazi Uni. 14(3):897-906 (2001).

After the reconstruction of education faculties in Turkey in 1997, he, like some mathematicians in the USA and Germany, started to research in the area of mathematics education. As a full professor at the Gazi University, a state university with the largest teacher preparation program, he successfully initiated a Ph.D. program in mathematics education, which has led to success. Under his supervision, several Ph.D. and master theses have been completed in research topics such as learning difficulties in algebra, teaching of algebraic concepts, cooperative learning, metacognitive behaviors, visual modeling as a component of pedagogical content knowledge, problem posing, problemsolving strategies, the usage of visualization in abstractions and generalizations of mathematical concepts, students' internal and external representations related to some mathematical concepts, concept images of prospective secondary mathematics teachers and teaching of limit concept related to the functions of one and two variables. Some published articles related to mathematics education are:

1. Foto-Mat Project and the views of prospective mathematics teachers about Foto-Mat project. Hacettepe Uni. Jour. of Education (27):30-39.
2. Why The students have difficulty with algebra. Haccettepe Uni. Journal of Education 24:180-185 (2003).

3. 9-grade students' difficulties in arithmetic operations, ordering numbers, the solving equations and inequalities. Haccettepe Uni. Journal of Education, (32):274281 (2007).

4. Effect of "student's teams-achievement divisions" method based instruction on mathematics academic achievement and self efficacy. Hacettepe Uni. Journal of Education (35):307-318 (2008).

The other co-editor, Behiye Ubuz, holds a B.Sc. and M.Sc. from the Middle East Technical University (METU) at Ankara, and a Ph.D. from Nottingham University in the UK. She specializes in mathematics education and is an associate professor at Middle East Technical University. Her research interests include various aspects of teaching and learning of mathematics, particularly calculus, geometry, fractions, decimals and algebra. She has successfully published papers in numerous English language periodicals and in various international journals such as Journal of Computers in Mathematics and Science Teaching, The Journal of Mathematical Behavior and Academic Exchange Quarterly, and in Turkish language journals such as Egitim Fakültesi Dergisi, Egitim ve Bilim, Ilkögretim online, Ondokuz Mayis Universitesi Egitim Fakültesi Dergisi, Pamukkale Üniversitesi Egitim Fakültesi Dergisi, Yaratici Drama Dergisi and Matematik Dünyasi. Currently, she is working on proof and proving in algebra, geometry, etc.; cognitive demands in tasks; pre-service teachers' knowledge on functions and geometry, etc., and supervising six Ph.D. theses at METU.

In the next section, I briefly summarize some innovative and influential ideas that have come out of doctoral education programs in Turkey, particularly at the Gazi University, which has spearheaded efforts at following qualitative methodologies in addition to setting a foundational base in the quantitative paradigm.

\section{Doctoral dissertations}

Yüksel Dede (2003), "The influence of teaching approach based on ARCS motivation model and Component display theory on the students 'learning level related to concept of the variable and students' motivation", doctoral dissertation, Gazi University, Institute of Educational Sciences.

The main aim of Dede's study was to investigate the influence of teaching approach, which is based on Keller's (1987) $\mathrm{ARCS}^{3}$ motivation model and component display theory on students learning levels related to the concept of

\footnotetext{
3 The ARCS model was developed by Keller. ARCS stands for attention, relevance, confidence and satisfaction.
} 
the variable and students' motivation. The research was carried out in two phases, with quantitative and qualitative methods. In the qualitative part, the misunderstandings and the misconceptions of students related to the concept of the variable was investigated using a test, which included 26 open-ended questions. This test was administered to eighth grade students. In the quantitative part, the effect of the ARCS motivation model and component display theory was investigated. To do this, lessons were planned based on the ARCS Motivation Model and Component Display Theory and they were applied to the students of eighth grade.

Handan Demircioğlu (2008), "Effectiveness of educational events designed for the development of metacognitive behaviors of prospective mathematics teachers", doctoral dissertation. Gazi University, Institute of Educational Sciences.

The aim of Demircioglu's study was to design educational events for the development of metacognitive behaviors (that is metacognitive knowledge and skills), to implement these educational events and to investigate the effects of these events on the behaviors of prospective mathematics teachers. The designed educational events included different techniques such as writing, thinking aloud, pair problem solving and action card. This study was organized in eight meetings (4 with writing, 2 with think aloud protocol, 1 of with paired problem solving and 1 with action cards) during the implementation of the entire processes. The data were collected through observations, written documents, think aloud protocol, videotapes and audiotapes of semi-structured interviews. The findings obtained indicated that having these carefully organized experimental studies improved the participants' knowledge about themselves, and increased their metacognitive behaviors and awareness. Also, after these experiments, participants began to work in critically self-reflective ways, used control strategies and understood impediments to their success in the past.

\subsection{The transformation of doctoral dissertations from Turkish to English}

It was a trend for mathematics education researchers such as many of the authors in this issue to receive their training abroad, either in the UK or the USA for their terminal degrees. Many of the authors in this issue received their Ph.D. in the USA and UK. However, with the systematic establishment of researchers within a core group of universities such as Gazi and METU, this trend has changed. In two recently completed dissertations at Gazi, for which I served in an advisory capacity as an officially appointed committee member, the constructs of infinity and creativity were explored in great depth. What is special about these dissertations is that the Ph.D. students conducted a part of the writing in English as opposed to only using Turkish.

Serdar Aztekin (2008), "The Constructs of PhD Students about Infinity: An Application of Repertory Grids", doctoral dissertation, Gazi University, Institute of Educational Sciences.

Aztekin's dissertation tackled the concept of infinity, first with a pilot study in young children through the use of animations and then compared it to the understanding of research-level mathematics graduate students who had been exposed to formal set theory. His study yielded insights into the constructs about infinity held by Ph.D. students, as well as investigated the effects of the set theory course on their informal models. This was achieved by using an innovative technique called repertory grid methodology as a way of capturing the constructs of students. A major component of the research on mathematics education related to infinity has been the study of student's conceptions and reasoning on calculus subjects, particularly limits and series. Some related studies are about Cantor's ordinal and cardinal infinity. However, since most students at the high school and college level are unfamiliar with symbolic representations and terminology, such as a set theoretic approach, a context (generally geometric) was used for investigating notions of infinity indirectly. It was found that the Ph.D. students in the study had an understanding of potential infinity and, after the set theoretic lessons, there was emerging evidence of the notion of actual infinity. One result was the tendency of interpreting different infinities, which indicate element numbers of different infinite sets via countability and uncountability of sets. The other important result was about teaching of set theory topics. It was observed that students found ordinality more difficult than cardinality as in previous studies (Tirosh, 1991). Finally, Aztekin suggested repertory grid methodology (Fransella \& Bannistar, 1977) as a way of capturing the constructs of students and argued that this methodology could help us to learn further details about the understanding of infinity. This dissertation has resulted in the exploration and development of repertory grid methodology as a robust means of combining qualitative and quantitative paradigms for researching cognition in mathematics education (Aztekin, Arikan \& Sriraman, 2010)

Yasemin Kiymaz (2009), A qualitative study of preservice secondary mathematics teachers' mathematical creativity in problem solving situations, doctoral dissertation, Gazi University, Institute of Educational Sciences.

The main aim of this study was to extend the framework developed in Sriraman's (2009, reprint of 2004) study on mathematical creativity and to determine the characteristics of creative thinking skills developed by secondary mathematics prospective teachers during the process of mathematical problem solving. The study was motivated by the 
fact that although research mathematical activities are nested within creativity, the schools provide insufficient experiences related to creativity in mathematics. The main aim of the dissertation study was to determine pre-service secondary mathematics teachers' creative thinking skills when presented with different mathematical problem-solving situations. Creative thinking was operationalized in terms of fluency, flexibility and originality, and examined using qualitative research methodology. A total of 22 pre-service secondary mathematics teachers participated in this study during their optional course called 'Selected Topics in Mathematics'. To obtain in-depth knowledge and triangulation criteria, data included classroom observations, preservice teachers' journals and semi-structured interviews. Coding techniques from grounded theory were used in the data analysis. The results of this study pointed out a number of issues related to mathematical creativity. It was found that pre-service teachers developed various problem-solving behaviors in different mathematical problem situations, but also encountered various difficulties due to the types of algorithmic strategies used and the dead ends that some of these strategies led to. The research findings also pointed out that creative thinking skills in terms of fluency, flexibility and originality mainly depended on personal and extracognitive factors.

\section{Developing the issue: the need for quality and coherence}

As stated earlier, this special issue of ZDM was conceived as a result of my visiting appointments at the Gazi University in Turkey over the course of three summers, during which time I served as a member of different thesis committees and as an academic collaborator. Having reported on some of the outcomes in the previous sections of this introduction, I now turn to the focus of this issue per se. The goal of this issue was to share some prototypical examples of research conducted in Turkey in mathematics education. For this reason, the issue editors planned an issue that originally cohered around the themes of cognition and curriculum, areas which have been researched extensively in Turkey. The papers solicited for this issue were meant to convey the state of research in the following areas in Turkey:

- history of mathematics education in Turkey in the context of K-12 mathematics curricula;

- the story of change in the nationally unified curricula of Turkey and the quality of mathematical tasks in this new Turkish school mathematics curricula;

- the structure of metacognitive behaviors displayed in the process of problem solving of prospective mathematics teachers in Turkey.
The opening article, A Brief History of Mathematics Education in Turkey: K-12 Mathematics Curricula, gives a brief history of mathematics education in Turkey. The purpose is not to detail the whole history of Turkish education, but to give a snapshot of the history of Turkish mathematics education in the last century. In this context, the authors (Argün, Arikan, Bulut and Sriraman) underline some important events and eras that have affected the national education movements in Turkey from the curriculum development perspective, since one of the main goals in this issue of ZDM is to share some prototypical examples of research conducted in Turkey in mathematics education. This article provides the reader with a general perspective for the historical development of K-12 mathematics curricula with respect to their philosophies, goals, objectives, instruction and assessment as opposed to a comprehensive analysis of the mathematics education in Turkey, so that the ensuing articles included in this issue can be understood more deeply and clearly. The second article, "A micro-curricular analysis of unified mathematics curricula in Turkey", gives a brief description of the educational system in Turkey and is explicated on the main tenets of unified curriculum, especially in the area of mathematics. In this article, Zembat conducts an analysis of a newly developed mathematics curriculum that has been under revision for the last 5 years and being implemented for the last 3 years. The article includes an analysis of a sample lesson from a newly developed textbook written by the scholars working for the Ministry of Education and approved by the ministry. In a sense, Zembat tries to give the reader a picture of the issues regarding the lack of connection among the intended, written and implemented curricula in the area of mathematics using the case of Turkey.

Two examples of research using phenomenological/ hermeneutic methods are found in this issue, namely Inan and Dogan-Temur's “Understanding Kindergarten Teachers' Perspectives of Teaching Basic Geometric Shapes: a Phenomonographic Research" and Taşar's article entitled "What Part of the Concept of Acceleration is Difficult to Understand: The Mathematics, the Physics, or both?" Both articles focus on specific content-related issues. The former is aimed at Turkish kindergarten classes and examines teachers' perspectives on teaching geometry in kindergarten classes using phenomenographic methods. The findings of this phenomenographic research indicated lack of deep content knowledge, a finding similar to those in other parts of the world in the sub-domain of the teaching of geometry. The latter piece focuses on an individual learner and attempts to understand why and how learning progresses in a particular direction and results in failure or success. Without posing a hypothesis, a freshman novice college student's lines of thought and reasoning regarding force 
and motion in particular situations are investigated to portray an example of such learning. From a mathematics teaching point of view, Taşar considered velocity and acceleration as primary examples for students to truly comprehend the meaning of the concept of rate of change. The author reports that both velocity and acceleration are rate of change type concepts. But while students can learn the former relatively easily, as demonstrated here, the latter causes a lot of conceptual difficulties. This study was the doctoral thesis of Taşar, conducted in the USA, and is included in the issue as an example of Turkish doctoral student's exposure to qualitative methods outside their country.

The fifth article by Ubuz et al., entitled Exploring the quality of the mathematical tasks in the new Turkish elementary school mathematics curriculum guidebook: the case of algebra, is a prototypical example of a contentrelated curriculum analysis in relation to the place of algebra in the elementary school curriculum.

Finally, the last article entitled, "A Case Study: Assessment of Preservice Secondary Mathematics Teachers' Metacognitive Behaviors in Problem Solving Process", focuses on how pre-service secondary mathematics teachers' metacognitive behaviors change in solving different types of mathematical problems. The authors Demircioğlu, Argün and Bulut try to answer the following questions:

1. How do the pre-service secondary mathematics teachers' metacognitive behaviors change in solving mathematical problems when accounting for all possibilities of strategies with respect to achievement?

2. How do the pre-service secondary mathematics teachers' metacognitive behaviors change in solving mathematical problems when making a drawing, and intelligent guessing-testing strategies with respect to achievement?

To investigate these problems, an exploratory case study methodology was used with 45 mathematics pre-service teachers. Existing problem-solving frameworks were operationalized to research and analyze participants' think aloud protocols. As a consequence of the analysis, it was found that there was no relationship between academic achievement and frequencies of metacognitive behaviors.

The papers submitted for the issue were subject to rigorous review, which resulted in acceptance (and improvement) of many and rejection of others. The selection process began with the submission of 15 abstracts, from which 12 were invited to submit full papers. After two rounds of peer review, including numerous rewrites and revisions, six papers were accepted, which significantly advanced our understanding of what characterized mathematics education research in Turkey today. The value of the set of papers lies in their exploration of history, curriculum and cognition. Some of the papers in this issue cover research and history of curriculum, whereas the others focus on specific implementation issues of content such as geometry and algebra in the curriculum.

\section{Concluding notes}

Mathematics education in Turkey follows the natural progression of development as witnessed in numerous countries such as the USA, Australia, UK and Germany. The field originated with the work of mathematicians who turned into pedagogues and with ensuing generations becoming more trained and proficient through terminal degrees in mathematics education from the USA, UK and also Turkey. Researchers in Turkey are also gradually moving from topics researched in other parts of the world such as affect, metacognition and problem solving as well as gender issues using quantitative methodologies onto more qualitatively oriented methods such as repertory grid methodology (Aztekin, Arikan, Sriraman, 2010), grounded theory and phenomenological methods to explore more complex and nuanced phenomenon such as creativity. Research on curriculum has also been traditionally robust and continues in addition to large-scale studies on gender issues (e.g., Bulut, Bekir, Sriraman, 2010).Turkey is a very "young" country in terms of its demographics with many talented and energetic students in mathematics education and other fields. I anticipate many of them making good contributions to scholarship and curriculum development. On a larger scale, the infrastructure and economy of the country is booming and there is a vibrant energy about it. However, it still remains unclear whether the EU will judge Turkey for its secular, economic, political and institutional merits and offer it membership, or whether the collective consciousness of the EU is still haunted by the Osmanli flag flying across the Danube during the last siege of Vienna in 1683 (Sriraman, 2008). Only time will tell!

Acknowledgments The author thanks Gazi University, their mathematics education faculty and the doctoral students at the Institute of Educational Sciences for their hospitality during my visits. In particular, I am grateful to Ziya and Gulfer Argun, Ahmet and Aynur Arıkan, and Yasemin and Onur Kiymaz for immersing me into the Turkish language and culture and making me a part of their families. In addition, Rezzan Yilmaz, Hakan Sandir and numerous others that I have forgotten to name here have been extremely generous with their time and grace during my visits. I wish to acknowledge and thank numerous mathematics educators in Turkey and in other parts of the world that played a pivotal behind the scenes role in improving the manuscripts, besides the hundreds of hours spent by the author to provide writing support, compile, edit and language corrections needed for this issue. The 30 reviewers who played a role through many rounds of reviews to help authors improve their papers will be acknowledged at the end of the year. The efforts of several Turkish 
colleagues to conduct English language corrections for various authors in the issue is also much appreciated. Several international reviewers reported to me the learning experience of understanding the depth, the history and the complexities of mathematics education in Turkey.

\section{References}

Aztekin, A., Arikan, A., \& Sriraman, B. (2010). The constructs of PhD students about infinity: An application of repertory grids. The Montana Mathematics Enthusiast, 7(1), 149-174.

Bulut, S., Bekir, G., \& Sriraman, B. (2010). Commentary 2 on feminist pedagogy and mathematics-mathematics achievement and gender: A case of "No Difference" from Turkey. In B. Sriraman \& L. English (Eds.), Theories of mathematics education: Seeking new frontiers (pp. 455-466). Berlin: Springer.
Fransella, F., \& Bannistar, D. (1977). A manual for repertory grid technique. New York: Academic Press.

Keller, J.M. (1987). Development and use of the ARCS model of motivational design. Journal of Instructional Development, 10(3), 2-10.

Said, E. (1979). Orientalism. USA: Pantheon Books.

Sriraman, B. (2007). Mathematics, culture and language: Musings on Turkey-the crossroads of civilization. Expanding Horizons: The University of Montana Newsletter, November, p. 2.

Sriraman, B. (2008). Touching Turkey's timeless Osmanli soul. This IS Central and Southwest Asia: The University of Montana Newsletter, pp. 6-7.

Sriraman, B. (2009). The characteristics of mathematical creativity. ZDM, 41(1 and 2), 13-27.

Tirosh, D. (1991). The role of students' intuitions of infinity in teaching the Cantorian theory. In D. Tall (Ed.), Advanced mathematical thinking (pp. 201-214). The Netherlands: Kluwer. 